\title{
PENGARUH MOTIVASI, KOMPENSASI, DAN LINGKUNGAN KERJA FISIK TERHADAP SEMANGAT KERJA KARYAWAN BELLO DESAIN DI SINGARAJA
}

\author{
Luh Putu Octaviani ${ }^{1}$ \\ I Wayan Suana ${ }^{2}$ \\ ${ }^{1,2}$ Fakultas Ekonomi dan Bisnis Universitas Udayana (Unud), Bali, Indonesia \\ email: putuoctaviani97@gmail.com
}

\begin{abstract}
ABSTRAK
Karyawan merupakan sumber daya yang berperan penting dalam menunjang tercapainya keberhasilan perusahaan. Maka dari itu, perusahaan harus memperhatikan faktor-faktor yang mempengaruhi karyawan dalam bekerja. Faktor motivasi yang baik, kompensasi yang sesuai, dan lingkungan yang baik dapat meningkatkan semangat kerja karyawan Bello Desain Singaraja. Jenis data yang digunakan adalah data kualitatif yang bersumber dari data perspektif responden dan gambaran umum perusahaan, dan data kuantitatif adalah jumlah karyawan. Responden sebanyak 35 karyawan. Pengumpulan data menggunakan metode wawancara dan metode kuesioner. Teknik analisis data yang digunakan adalah analisis regresi linier berganda. Berdasarkan hasil analisis ditemukan bahwa motivasi berpengaruh positif dan signifikan terhadap semangat kerja, kompensasi berpengaruh positif dan signifikan terhadap semangat kerja, dan lingkungan kerja berpengaruh positif dan signifikan terhadap semangat kerja. Hasil penelitian mengimplikasikan bahwa semakin termotivasi karyawan terhadap pekerjaannya maka semangat kerjanya juga tinggi, kompensasi yang baik dapat meningkatkan semangat kerja, dan lingkungan kerja yang baik dapat meningkatkan semangat kerja.
\end{abstract}

Kata kunci : Semangat Kerja, Motivasi, Kompensasi, dan Lingkungan Kerja

\begin{abstract}
Employees are resources that play an important role supporting achievement of company. companies must pay attention to factors that influence employees in their work. Good motivation factors, appropriate compensation, and good environment can enhance the work morale of Bello Design employees. 35 respondents were used. Data collection using interview methods and questionnaire methods. The data analysis technique used is multiple linear regression analysis. Based on the results of the analysis found that motivation has a positive and significant effect on morale, compensation has a positive and significant effect on morale, and the work environment has a positive and significant effect on work morale. The results of the study imply that the more motivated employees are towards their work, the work enthusiasm is also high, good compensation can increase morale, and a good work environment can increase morale.

Keywords: work morale, motivation, compensation, work environment
\end{abstract}




\section{PENDAHULUAN}

Globalisasi merupakan realita yang harus dihadapi oleh perusahaan untuk tetap dapat mempertahankan diri dari tekanan eksternal maupun internal dari perusahaan. Banyak usaha baru yang terdapat di Indonesia dengan berbagai jenis usaha yang diharapkan memberikan lapangan pekerjaan bagi masyarakat pengangguran di Indonesia. Salah satu usaha yang membantu mengurangi pengangguran yang ada di Indonesia yaitu usaha Desain Interior, karena usaha ini memiliki banyak divisi tugas sehingga banyak pula memerlukan tenaga sumber daya manusianya.

Keberadaan desain interior penting di dalam masyarakat karena desain interior yang baik dan sempurna memiliki dampak pada kesehatan tubuh seseorang. Secara fisiologis, maupun psikologis, kesehatan seseorang dapat terpengaruh oleh suasana dan nuansa sebuah ruangan.

Kreativitas menjadi salah satu daya tarik bagi sebuah desain. Tinggi rendahnya kreativitas desain yang diciptakan ditentukan oleh karyawan. Karyawan akan berkreativitas tinggi apabila mereka memiliki semangat kerja yang tinggi pada organisasi. Suatu organisasi yang baik, perlu adanya suatu pembinaan dan pemanfaatan sumber daya manusia untuk dapat menghasilkan tenaga kerja yang berkualitas, sehat jasmani, dan rohani, serta memiliki keterampilan yang baik.

Bello Desain merupakan perusahaan yang bergerak dibidang jasa pembuatan seperti desain arsitektur dan interior, yang tentunya mengalami persaingan yang cukup ketat dikarenakan terdapat banyak usaha yang sejenis di Bali. Agar Bello Desain tetap mampu bersaing dengan para pesaingnya, maka Bello Desain harus mampu mengoptimalkan seluruh sumber daya yang dimiliki.

Semangat kerja adalah kemampuan seseorang atau kelompok untuk bekerja dengan giat dalam mengejar tujuan bersama, sehingga pekerjaan dapat diselesaikan lebih cepat serta mendapatkan hasil yang memuaskan. Jika semangat kerja rendah, kemungkinan partisipasi hanya akan terbatas pada apa yang diperintahkan. Semangat kerja yang rendah ditandai dengan kegelisahan, yaitu perpindahan, ketidak hadiran, keterlambatan, ketidak disiplinan, dan menurunnya hasil kerja (Utamajaya \& Sriathi, 2015)

Terdapat banyak penelitian yang mengidentifikasi variabel apa saja yang mempengaruhi semangat kerja karyawan. Terdapat beberapa variabel yang mempengaruhi semangat kerja karyawan meliputi: motivasi, kepemimpinan, komunikasi, hubungan manusia, partisipasi, lingkungan kerja fisik, kompensasi, kesehatan, dan keselamatan.

Dengan meningkatnya semangat kerja maka pekerjaan akan lebih cepat terselesaikan, absensi dapat dikurangi, kerusakan barang akan dapat dikurangi dan kemungkinan perpindahan karyawan dapat diperkecil. Untuk menumbuhkan semangat kerja tentunya motivasi menjadi salah satu faktor penimbang dalam pendorong semangat kerja. Motivasi mempengaruhi semangat kerja, apabila motivasi baik maka semangat kerja akan meningkat, begitu pula apabila motivasi tidak baik maka semangat kerja akan menurun

Kompensasi juga mempengaruhi semangat kerja. Syahreza et al. (2017) mengatakan Kompensasi sangat penting bagi karyawan, karena dengan adanya kompensasi yang seimbang dapat meningkatkan semangat kerja karyawan dan 
loyalitas karyawan terhadap pekerjaannya akan terjaga agar karyawan tidak berpindah tempat kerja. Dengan demikian kompensasi merupakan salah satu faktor penting dalam suatu perusahaan (Widiantara \& Wasnury, 2015)

Faktor lain yang mempengaruhi semangat kerja adalah lingkungan kerja fisik. Lingkungan kerja adalah lingkungan yang mempengaruhi pembentukan perilaku seseorang dalam bekerja, lingkungan kerja dibagi menjadi dua yaitu lingkungan kerja non fisik adalah rasa aman dari bahaya, aman dari pemutusan kerja, loyalitas baik kepada atasan maupun sesame rekan kerja dan adanya rasa kepuasan kerja dilingkungan karyawan. Sedangkan lingkungan kerja fisik adalah bangunan dan fasilitas yang disediakan serta letak gedung dan prasarananya

Berdasarkan wawancara yang dilakukan kepada pimpinan perusahaan bahwa ditemukannya hasil kerja karyawan menurun atau banyaknya keluhan yang dikeluhkan oleh konsumen mengenai tidak tepat waktunya karyawan menyelesaikan pekerjaanya yang diakibatkan oleh kurangnya semangat kerja yang dimiliki oleh karyawan.

Menurunnya semangat kerja ini disebabkan oleh kurangnya motivasi yang diberikan oleh perusahaan, tidak diberikan uang lembur dan kurangnya fasilitas kerja yang diberikan agar karyawan lebih mudah bekerja. Sedangkan dari pihak perusahaan sudah memberikan gaji seuai dengan jabatan yang dimiliki agar karyawan semangat didalam bekerja.

Berdasarkan latar belakang yang sudah dijabarkan tersebut, maka dapat dirumuskan masalah penelitiannya sebagai berikut: 1) Apakah motivasi berpengaruh positif terhadap semangat kerja karyawan? 2) Apakah kompensasi berpengaruh positif terhadap semangat kerja karyawan? 3) Apakah lingkungan kerja fisik berpengaruh positif terhadap semangat kerja karyawan?

Berdasarkan dari latar belakang dan rumusan masalah yang sudah dijabarkan di atas, maka tujuan penelitian ini adalah sebagai berikut: 1) Untuk menganalisis pengaruh motivasi terhadap semangat kerja karyawan. 2) Untuk menganalisis pengaruh kompensasi terhadap semangat kerja karyawan. 3) Untuk menganalisis pengaruh lingkungan kerja fisik terhadap semangat kerja karyawan.

Hasil dari penelitian ini diharapkan dapat memperkuat bukti empiris yang ada dan dapat memberikan sumbangan masukan dalam membangun semangat kerja karyawan di Bello Desain Singaraja.

Teori yang digunakan dalam penelitian ini adalah Hierarki kebutuhan Abraham Maslow dimana ia mengembangkan teori tentang bagaimana semua motivasi saling berkaitan. Kebutuhan ini memiliki tingkat yang berbeda-beda. Ketika satu tingkat kebutuhan terpenuhi, orang tidak mendapat lagi motivasi dari kebutuhan tersebut. (Gîlmeanu, 2015)

Setiap diri manusia terdapat lima kebutuhan meliputi kebutuhan fisiologis, kebutuhan makan, minum, perlindungan fisik, seksual, sebagai kebutuhan terendah. Kebutuhan rasa nyaman dan aman berupa perlindungan, keselamatan kerja, jaminan berlangsungnya pekerjaan dan jaminan di hari tua.

Kepemilikan Sosial menyangkut kebutuhan untuk diterima dalam kelompok, berafiliasi, berinteraksi, dan kebutuhan untuk dicintai dan mencintai. Penghargaan diri yang meliputi kebutuhan akan harga diri, kebutuhan dihormati dan dihargai oleh orang lain. 
Orang akan berusaha untuk memenuhi tingkat berikutnya. Dari lima tingkatan kebutuhan yang dikemukakan Abraham Maslow akan berkaitan dengan bagaimana terpenuhinya setiap tingkatan kebutuhan karyawan melalui motivasi yang akan menimbulkan rasa semangat kerja yang tinggi pada diri karyawan. Setiap kebutuhan tersebut berkaitan dengan bagaimana menciptakan motivasi, kompensasi, dan lingkungan kerja fisik yang baik dan tepat untuk perusahaan.(Osa \& Amos, 2014)

Semangat kerja merupakan kegiatan melakukan pekerjaan lebih giat, dengan hal tersebut diharapkan apapun pekerjaan yang dilakukan dapat lebih cepat diselesaikan dan akhirnya akan memperoleh hasil yang memuaskan. Semangat kerja merupakan kemampuan seseorang untuk melalukan kerjasama secara konsekuen dan giat dalam hal mengejar tujuan yang telah ditetapkan. Semangat kerja adalah kemauan untuk melakukan pekerjaan dengan giat dan antusias, sehingga penyelesaian pekerjaan cepat dan baik. Mengukur semangat kerja dengan beberapa tanda positif dan negatif dalam sikap dan perilaku seseorang.

Motivasi merupakan dorongan untuk memenuhi sebuah tujuan tertentu yang ditandai dengan sebuah tindakan dimana motivasi merupakan proses mengarahkan perilaku dan kinerja. Motivasi sangat dibutuhkan di dalam sebuah organisasi dalam meningkatkan semangat kerja para karyawannya. (Elqadri \& Wardoyo, 2015)

Terdapat penelitian terdahulu mengenai hubungan antara motivasi terhadap semangat kerja yang menyatakan bahwa terdapat hubungan positif diantara keduanya. Motivasi merupakan aspek penting dalam mendorong karyawan untuk mencapai kinerja yang optimal. Motivasi bisa berasal dari diri sendiri ataupun dari dukungan yang diberikan oleh orang lain. (Chukwuma, 2014)

Omolo (2015) menyatakan bahwa motivasi berpengaruh terhadap semangat kerja, motivasi dapat memperbaiki semangat dalam bekerja. Apabila motivasi baik maka semangat kerja akan meningkat, begitu pula apabila motivasi tidak baik maka semangat kerja akan menurun.

Motivasi berpengaruh terhadap semangat kerja karyawan, motivasi rekan kerja memiliki dampak besar dalam semangat kerja. Pada lingkungan kerja, karyawan akan merasa lebih semangat dan penuh dengan antusias melaksanakan pekerjaannya apabila atasan atau rekan kerjanya memberikan perhatian kepada karyawan itu sendiri sehingga pekerjannya akan diselesaikan dengan efektif dan efisien.

Penelitian yang dilakukan oleh Kusuma (2016) di CV. F.A Management menyatakan bahwa motivasi memiliki pengaruh yang positif dan signifikan terhadap semangat kerja karyawannya, hasil ini juga sejalan dengan penelitian Shaban (2017) bahwa variabel motivasi dapat menjelaskan variabel semangat kerja secara dominan. Dari beberapa penelitian terdahulu dapat ditarik kesimpulan bahwa dengan motivasi yang baik, maka semangat kerja karyawan akan baik pula, sehingga dapat dikatakan bahwa motivasi memiliki pengaruh yang signifikan dan positif terhadap semangat kerja karyawan. Dari uraian tersebut dapat dirumuskan hipotesis sebagai berikut :

$\mathrm{H}_{1}$ : Motivasi berpengaruh positif terhadap semangat kerja

Berdasarkan penelitian yang dilakukan oleh Sudiardhita et al. (2018) menyatakan bahwa kompensasi berpengaruh positif terhadap semangat kerja. Hasil 
penelitian Sharm \& Pandey (2016) menyatakan bahwa kompensasi berpengaruh terhadap semangat kerja, kompensasi yang cukup dan promosi jabatan akan meningkatkan semangat kerja.

Hasil penelitian Banks et al. (2015) menyatakan bahwa kompensasi berpengaruh terhadap semangat kerja. Hasil penelitian Agustina \& Suryani (2016) menyatakan kompensasi berpengaruh terhadap semangat kerja, semangat kerja yang rendah di antara guru itu sebagian disebabkan oleh rendahnya kompensasi, ketidakamanan kerja, fasilitas pengajaran yang buruk dan kurangnya minat siswa dalam kelas, kesempatan promosi yang buruk dan kurangnya dukungan administratif.

Hasil penelitian Rawat (2015) menyatakan bahwa kompensasi berpengaruh terhadap semangat kerja, bila kompensasi yang diberikan tidak sesuai maka semangat kerja akan rendah. Hasil penelitian Pravasta \& Sintaasih (2014) menyatakan bahwa kompensasi berpengaruh terhadap semangat kerja.

$\mathrm{H}_{2}$ : Kompensasi berpengaruh positif terhadap semangat kerja

Lingkungan kerja fisik merupakan segala sesuatu yang berkaitan dengan tempat dimana karyawan melakukan aktivitasnya di sebuah organisasi. Lingkungan kerja fisik dapat mempengaruhi karyawan dalam melaksanakan tugas tugasnya di dalam organisasi. Ratnasari \& Sudjahjo (2017) mendukung hasil penlitian yang mengemukakan bahwa kepemimpinan transformasional dan lingkungan kerja berpengaruh positif terhadap semangat kerja.

Yasa \& Wibawa (2015) menyatakan bahwa lingkungan kerja fisik berpengaruh signifikan terhadap semangat kerja. Lingkungan kerja yang baik akan berdampak langsung terhadap hasil kerja karyawan. Hasanah (2016) dan Riyanto et al. (2017) menyatakan lingkungan kerja yang baik dan mendukung dapat meningkatkan semangat kerja karyawan, karena dengan adanya lingkungan serta fasilitas yang lengkap dan mendorong karyawan untuk melaksanakan tugasnya dengan baik, merasa senang dan tidak malas, sehingga memacu semangat kerja karyawan untuk melaksanakan pekerjaannya.

Penelitian Annisa (2015) meungkapkan bahwa dengan memperhatikan lingkungan kerja yang baik atau menciptakan kondisi kerja yang mampu memberikan motivasi untuk bekerja, maka akan membawa pengaruh terhadap kegairahan atau semangat kerja.

Setiap perusahaan harus terus selalu berusaha untuk menciptakan dan memelihara lingkungan kerja yang baik agar karyawan dapat bekerja dan nyaman, tenteram dan stabil dengan yang diharapkan sehingga memungkinkan untuk dapat meningkatkan prestasi kerja yang baik dan dapat menghasilkan produk yang bagus (Ependi, 2014). Dari uraian tersebut dapat dirumuskan hipotesis sebagai berikut : $\mathrm{H}_{3}$ : Lingkungan kerja fisik berpengaruh positif terhadap semangat kerja

\section{METODE PENELITIAN}

Penelitian ini menggunakan pendekatan kuantitatif dan termasuk ke dalam penelitian asosiatif (hubungan) yang bertujuan untuk mengetahui hubungan di antara tiga variabel atau lebih. Jenis penelitian ini adalah liniear karena bertujuan untuk mengetahui pengaruh variabel bebas (motivasi, kompensasi dan lingkungan kerja fisik) terhadap variabel terikatnya (semangat kerja). 
Penelitian ini dilaksanakan di perusahaan Bello Desain yaitu dijalan Yudistira Singaraja Bali. Perusahaan ini dipilih karena ditemukan masalah-masalah yang berkaitan dengan motivasi, kompensasi, dan lingkungan kerja fisik terhadap semangat kerja karwayan.

Subjek yang akan diteliti dalam penelitian ini adalah karyawan Bello Desain, sedangkan objek dari penelitian adalah motivasi, kompensasi, lingkungan kerja fisik dan semangat kerja. Dalam penelitian ini yang menjadi variabel terikat adalah semangat kerja (Y). Dalam penelitian ini, variabel bebas adalah motivasi $\left(\mathrm{X}_{1}\right)$, kompensasi $\left(\mathrm{X}_{2}\right)$, dan lingungan kerja fisik $\left(\mathrm{X}_{3}\right)$.

Semangat kerja merupakan keinginan dan kesungguhan seseorang dalam mengerjakan pekerjaannya meliputi perasaan seorang individu terhadap pekerjaan dan organisasinya. Semakin semangat seorang individu dalam mengerjakan pekerjaannya, maka akan semakin baik pula kinerja dari individu tersebut di dalam organisasinya.

Indikator yang mempengaruhi variabel semangat kerja yaitu: Tingkat kehadiran karyawan, Melaksanakan pekerjaan tepat waktu, Tidak meninggalkan tempat kerja pada waktu kerja, Melaksanakan pekerjaan sesuai instruksi atasan, Kepuasan terhadap pembagian tugas

Motivasi adalah suatu dorongan atau alasan yang menjadi dasar semangat seseorang untuk melakukan sesuatu sehingga menghasilkan tingkat kinerja yang optimal. Indikator yang mempengaruhi variabel motivasi yaitu: Penempatan kerja yang tepat, Kondisi pekerjaan yang nyaman, Fasilitas rekreasi, Jaminan kesehatan.

Kompensasi adalah imbalan yang diberikan perusahaan atau organisasi atas dasar hasil yang mampu dicapai oleh karyawan bersangkutan. Indikator yang mempengaruhi variabel kompensasi yaitu: Upah dan gaji, Insentif, Tunjangan, Fasilitas

Lingkungan kerja fisik adalah segala sesuatu yang terdapat disekitar lingkungan pegawai yang berpengaruh terhadap pelaksanaan dan penyelesaian tugas dan tanggung jawab yang dibebankan. Lingkungan kerja fisik dideskripsikan sebagai hal fisikyang terdapat dilingkungan pekerja. Indikator yang mempengaruhi variabel lingkungan kerja fisik yaitu: Penerangan di tempat kerja, Temperatur di tempat kerja, Sirkulasi udara di tempat kerja, Kebisingan di tempat kerja, Keamanan di tempat kerja, Rekan Kerja, Fasilitas kerja. Dalam penelitian ini, data kuantitatif adalah seluruh data yang dihimpun dari kuesioner penelitian. Data kuantitatif yaitu data yang berbentuk angka atau data kualitatif yang di konversi menjadi angka. Sedangkan data kualitatif adalah data yang berbentuk gambar, bagan, atau data yang tidak memiliki unsur angka. Dalam penelitian ini, data kualitatif yaitu sejarah berdirinya dan struktur organisasi Bello Desain.

Data yang digunakan dalam penelitian ini adalah sumber primer yang berbentuk kuantitatif yang nantinya akan dikumpulkan menggunakan penyebaran kuesioner pada responden yang sudah ditentukan. Sumber sekunder yang digunakan dalam penelitian ini adalah buku-buku literature dan sejarah beserta struktur organisasi perusahaan.

Instrumen penelitian berupa kuesioner, yang terdiri atas pertanyaan tertutup serta pertanyaan terbuka. Pertanyaan tertutup terdiri atas beberapa pertanyaan tentang identitas responden, sedangkan pertanyaan terbuka terdiri atas sejumlah 
pertanyaan yang meminta pendapat responden tentang penilaiannya terhadap sejumlah indikator dari setiap variabel.

Indikator yang dinilai berupa indikator semangat kerja, motivasi, kompensasi, dan lingkungan kerja fisik. Pertanyaan terbuka pada kuesioner ini diukur dengan menggunakan skala Likert dengan skala 1 sampai 5.

Populasi dalam penelitian ini adalah seluruh karyawan Bello Desain berjumlah 35. Karena seluruh anggota populasi dijadikan sebagai sampel penelitian, maka penelitian ini dapat dikategorikan pada penelitian dengan sampel jenuh. Jumlah karyawan Bello Desain dapat dilihat pada tabel 1

Tabel 1.

Jumlah Karyawan di Bello Desain 2018

\begin{tabular}{clcc}
\hline No. & & Jabatan & Jumlah \\
\hline 1 & Sekretaris & 1 \\
2 & Bendahara & & 2 \\
3 & Desainer & 4 \\
4 & Manajer Pemasaran & 2 \\
5 & Manajaer Produksi & 22 \\
6 & Manajer Gudang dan Pembelanjaan & Total & 4 \\
& & & $\mathbf{3 5}$ \\
\hline
\end{tabular}

Sumber: Data primer diolah, 2018

Sampel dalam penelitian ini ditentukan dengan metode penyampelan jenuh (Saturated Sampling). Metode ini berarti bahwa seluruh populasi menjadi sampel penelitian. Metode pengumpulan data yang digunakan adalah Wawancara merupakan metode pengumpulan data dengan tanya jawab secara langsung dengan manajer Bello Desain. Pertanyaan dalam wawancara meliputi permasalahan ataupun keluhan karyawan yang berkaitan dengan semangat kerja kayawan, dan profil perusahaan.

Kuesioner merupakan metode pengumpulan data dengan menyebarkan daftar pertanyaan yang diberikan kepada responden berkaitan dengan semangat kerja karyawan Bello Desain.

\section{HASIL DAN PEMBAHASAN}

Bello Desain merupakan perusahaan yang bergerak dibidang jasa pembuatan bangunan seperti desain Arsitektur dan Interior Desain. Bello Desain Studio terletak di jalan Yudistira Singaraja Bali. Perusahaan ini sudah berdiri kurang lebih 5 tahun yang lalu tepatnya tahun 2013 yang awalnya studio ini terletak di jalan ayani gang wibisana no 5 Singaraja.

Pada awalnya Bello Desain memperkerjakan satu orang drafter yang merupakan anak didik dari Bapak Gede Indra Atmaja ST di sekolah SMKN 3 Singaraja. Seiring berjalannya waktu semakin berkembangnya proyek yang di pegang oleh Bello Desain Studio tentunya membutuhkan banyak karyawan. Sehingga sampai saat ini jumlah karyawan Bello Desain Studio berjumlah 35 orang.

Nama Bello diambil dari nama akrab dari owner Bello Desain Studio yaitu Gede Indra Atmaja ST yang dalam Bahasa jawanya artinya TINGGI disebutnya BELLO oleh rekan kuliahnya dikarenakan paling tinggi diantara temannya. Pada akhirnya owner memutuskan untuk menggunakan Nama Bello Desain Studio 
sebagai nama perusahaannya. Sampai saat ini Bello Desain Studio mampu bersaing di dunia jasa pembuatan bangunan arsitektur maupun interior baik dikawasan Kota maupun luar kota

Karakteristik responden merupakan indikator responden yang dikumpulkan untuk mengetahui profil responden penelitian. Data hasil penelitian yang dilakukan terhadap karyawan Bello Desain, maka dapat diketahui gambaran karakteristik responden yang meliputi empat aspek, yaitu: jenis kelamin, usia, pendidikan terakhir dan masa kerja. Jumlah responden yang digunakan dalam penelitian ini sebanyak 35 responden.

Tabel 2.

Karakteristik Responden Berdasarkan Jenis Kelamin

\begin{tabular}{cccc}
\hline No. & Jenis Kelamin & Jumlah Orang & Persentase \% \\
\hline 1. & Laki-laki & 30 & 85,72 \\
2. & Perempuan & 5 & 14,28 \\
& Total & $\mathbf{3 5}$ & $\mathbf{1 0 0}$ \\
\hline
\end{tabular}

Sumber: Data primer diolah, 2018

Dari data yang disajikan pada Tabel menunjukkan bahwa sebagian besar responden adalah laki-laki sebanyak 30 orang dengan persentase 85,72 persen, sedangkan sisanya perempuan sebanyak 5 orang dengan persentase 14,28 persen. Artinya sebagian besar karyawan Bello Desain Singaraja mempekerjakan tenaga laki-laki dikarenakan pekerjaan yang dilakukan itu lebih banyak menggunakan tenaga yang lebih besar.

Tabel 3.

Karakteristk Responden Berdasarkan Usia

\begin{tabular}{cccc}
\hline No. & Usia & Jumlah Orang & Persentase \% \\
\hline 1. & $21-25$ Tahun & 12 & 34,28 \\
2. & $26-30$ Tahun & 23 & 65,72 \\
& Total & $\mathbf{3 5}$ & $\mathbf{1 0 0}$ \\
\hline
\end{tabular}

Sumber: Data primer diolah, 2018

Dari data yang disajikan pada Tabel menunjukkan sebagian besar responden berusia diantara 26-30 tahun yaitu sebanyak 23 orang dengan persentase 65,72 persen, sedangkan sisa responden yang berusia 21-25 tahun yaitu sebanyak 12 orang dengan persentase 65,72 persen. Artinya sebagian besar karyawan disana berusai diantara 26-30 karena pengalaman kerja yang dimiliki lebih banyak.

Tabel 4.

Karakteristik Responden Berdasarkan Pendidikan Terakhir

\begin{tabular}{cccc}
\hline No. & Pendidikan Terakhir & Jumlah Orang & Persentase \% \\
\hline 1. & SMK & 27 & 77,14 \\
2. & S1 & 8 & 22,86 \\
& Total & $\mathbf{3 5}$ & $\mathbf{1 0 0}$ \\
\hline
\end{tabular}

Sumber: Data primer diolah, 2018

Dari data yang disajikan pada Tabel menunjukkan sebagian besar responden berdasarkan pendidikan terakhir adalah SMK sebanyak 27 orang dengan persentase 
77,14 persen dan sarjana (S1) sebanyak 8 orang dengan persentase 22,86 persen. Artinya sebagian besar karyawan disana pendidikan terakhirnya SMK, karena yang lulusan SMK hampir sama skillnya dengan yang pendidikan akhirnya S1 dibidang Drafter dan lebih mudah mengendalikan pikiran yang pendidikan akhirnya SMK dibandingkan yang S1, karena yang pendidikan akhirnya S1 itu sudah memiliki idialismenya sendiri.

Tabel 5.

Karakteristik Responden Berdasarkan Lama Bekerja Karyawan

\begin{tabular}{cccc}
\hline No. & Masa Kerja & Jumlah Orang & Persentase \% \\
\hline 1. & 1-2 Tahun & 21 & 60,00 \\
2. & 3-5 Tahun & 14 & 40,00 \\
& Total & $\mathbf{3 5}$ & $\mathbf{1 0 0}$ \\
\hline
\end{tabular}

Sumber: Data primer diolah, 2018

Dari data yang disajikan pada Tabel 5. menunjukkan sebagian besar responden telah bekerja selama 1-2 tahun yaitu sebanyak 21 orang dengan persentase 60,00 persen dan responden yang bekerja selama 3-5 tahun yaitu sebanyak 14 orang dengan persentase 40,00 persen. Artinya sebagian besar karyawan telah bekerja selama 1-2 tahun karena pekerjaan yang diberikan itu tidak sesuai dengan yang diingikan oleh perusahaan yang menyebabkan seringnya terjadinya pergantian karyawan dalam waktu diantara 1-2 tahun.

Tabel 6. menunjukkan bahwa setiap butir pernyataan pada kuesioner memiliki skor lebih dari 0,30. Hasil uji validitas menghasilkan korelasi terkecil sebesar 0,674 dan korelasi yang terbesar yaitu 0,892. Uji validitas menunjukkan bahwa kuesioner layak digunakan dalam penelitian ini.

Hasil uji reliabilitas yang disajikan dalam Tabel 7. menunjukkan bahwa seluruh instrumen penelitian memiliki koefisien Cronbach's Alpha lebih dari 0,6. Sehingga dapat dinyatakan bahwa seluruh variabel memenuhi syarat reliabilitas dan dapat digunakan dalam penelitian ini.

Dari data yang disajikan pada Tabel 8. menunjukkan bahwa tujuh pernyataan mengenai semangat karyawan memiliki total nilai rata-rata sebesar 3,76 yang berarti bahwa karyawan Bello Desain tergolong baik.

Nilai rata-rata tertinggi dimiliki oleh pernyataan 1 yaitu sebesar 4,11 yang memiliki arti bahwa karyawan selalu hadir setiap hari kerja yang menandakan bahwa karyawan memiliki semangat kerja yang tinggi. Namun dalam hal ini, pernyataan nomer 4 memiliki rata-rata nilai terkecil yaitu 3,46 yang memiliki arti bahwa karyawan mampu menyelesaikan tugas-tugas dengan cepat.

Penilaian responden dengan menggunakan 5 indikator ini terhadap variabel motivasi di Bello Desain terhadap semangat kerja yang dimiliki oleh karyawan dan dapat membantu perusahaan untuk meningkatkan semangat kerja yang dimiliki oleh karyawan. 
Tabel 6.

Hasil Uji Validitas Instrumen Penelitian

\begin{tabular}{|c|c|c|c|c|}
\hline No & Variabel & Item Pertanyaan & $\begin{array}{c}\text { Korelasi Item } \\
\text { Total }\end{array}$ & Keterangan \\
\hline \multirow{5}{*}{1} & \multirow{5}{*}{ Semangat Kerja (Y) } & $\mathrm{Y} .1_{.1}$ & 0,851 & Valid \\
\hline & & $Y_{.2}$ & 0,848 & Valid \\
\hline & & $Y_{.3}$ & 0,811 & Valid \\
\hline & & $Y_{.4}$ & 0,895 & Valid \\
\hline & & Y.5 & 0,758 & Valid \\
\hline \multirow{4}{*}{2} & \multirow{4}{*}{ Motivasi $\left(\mathrm{X}_{1}\right)$} & $\mathrm{X} 1.1$ & 0,893 & Valid \\
\hline & & $\mathrm{X} 1.2$ & 0,876 & Valid \\
\hline & & $\mathrm{X} 1.3$ & 0,838 & Valid \\
\hline & & $\mathrm{X} 1.4$ & 0,892 & Valid \\
\hline \multirow{4}{*}{3} & \multirow{4}{*}{ Kompensasi $\left(\mathrm{X}_{2}\right)$} & $\mathrm{X} 2.1$ & 0,775 & Valid \\
\hline & & $\mathrm{X} 2.2$ & 0,852 & Valid \\
\hline & & $\mathrm{X} 2.3$ & 0,879 & Valid \\
\hline & & $\mathrm{X} 2.4$ & 0,883 & Valid \\
\hline \multirow{7}{*}{4} & \multirow{7}{*}{ Lingkungan Kerja $\left(\mathrm{X}_{3}\right)$} & $\mathrm{X} 3.1$ & 0,674 & Valid \\
\hline & & $\mathrm{X} 3.2$ & 0,809 & Valid \\
\hline & & $\mathrm{X} 3.3$ & 0,835 & Valid \\
\hline & & X3.4 & 0,728 & Valid \\
\hline & & $\mathrm{X} 3.5$ & 0,800 & Valid \\
\hline & & $\mathrm{X} 3.6$ & 0,742 & Valid \\
\hline & & X3.7 & 0,827 & Valid \\
\hline
\end{tabular}

Sumber: Data primer diolah, 2018

Tabel 7.

Hasil Uji Reliabilitas

\begin{tabular}{cccc}
\hline No. & Variabel & Cronbach's Alpha & Keterangan \\
\hline 1 & Semangat Kerja $(\mathrm{Y})$ & 0,887 & Reliabel \\
2 & Motivasi $\left(\mathrm{X}_{1}\right)$ & 0,892 & Reliabel \\
3 & Kompensasi $\left(\mathrm{X}_{2}\right)$ & 0,867 & Reliabel \\
4 & Lingkungan Kerja $\left(\mathrm{X}_{3}\right)$ & 0,887 & Reliabel \\
\hline
\end{tabular}

Sumber: Data primer diolah, 2018

Dari data yang disajikan pada Tabel 9. menunjukkan bahwa empat pernyataan mengenai motivasi karyawan memiliki total nilai rata-rata sebesar 3,72 yang berarti bahwa karyawan Bello Desain tergolong baik.

Nilai rata-rata tertinggi dimiliki oleh pernyataan 1 yaitu sebesar 4,03 yang memiliki arti bahwa perusahaan menempatkan karyawan pada posisi yang tepat.Namun dalam hal ini, pernyataan nomer 2 memiliki rata-rata nilai terkecil yaitu 3,43 yang memiliki arti bahwa kenyamanan pada saat mengerjakan sesuatu perlu ditingkatkan.

Penilaian responden dengan menggunakan 4 indikator terhadap variabel kompensasi di Bello Desain ditunjukkan pada Tabel 10. Dari data yang disajikan pada Tabel 10. menunjukkan bahwa empat pernyataan mengenai kompensasi memiliki total nilai rata-rata sebesar 4,07 yang berarti bahwa karyawan Bello Desain tergolong baik. 
Tabel 8.

Jawaban Responden terhadap Semangat Kerja

\begin{tabular}{|c|c|c|c|c|c|c|c|c|c|}
\hline \multirow{2}{*}{ No } & \multirow{2}{*}{ Indikator } & \multicolumn{5}{|c|}{ Skor Jawaban } & \multirow{2}{*}{$\begin{array}{c}\text { Jumlah } \\
\text { Skor }\end{array}$} & \multirow{2}{*}{$\begin{array}{l}\text { Rata- } \\
\text { Rata }\end{array}$} & \multirow{2}{*}{ Kriteria } \\
\hline & & 1 & 2 & 3 & 4 & 5 & & & \\
\hline 1 & $\begin{array}{l}\text { Saya selalu hadir } \\
\text { setiap hari kerja }\end{array}$ & $\mathbf{0}$ & $\mathbf{0}$ & 11 & 9 & 15 & 144 & 4,11 & Baik \\
\hline 2 & $\begin{array}{l}\text { Saya selalu } \\
\text { masuk kerja tepat } \\
\text { pada waktunya }\end{array}$ & $\mathbf{0}$ & 1 & 12 & 11 & 11 & 137 & 3,91 & Baik \\
\hline 3 & $\begin{array}{l}\text { Saya mampu } \\
\text { menyelesaikan } \\
\text { pekerjaan yang } \\
\text { diberikan sesuai } \\
\text { dengan } \\
\text { kemampuan yang } \\
\text { dimiliki }\end{array}$ & $\mathbf{0}$ & 2 & 13 & 13 & 7 & 130 & 3,71 & Baik \\
\hline 4 & $\begin{array}{l}\text { Saya mampu } \\
\text { menyelesaikan } \\
\text { tugas-tugas } \\
\text { dengan cepat }\end{array}$ & $\mathbf{0}$ & 6 & 14 & 8 & 7 & 121 & 3,46 & Baik \\
\hline 5 & $\begin{array}{l}\text { Lingkungan kerja } \\
\text { yang nyaman, } \\
\text { bersih, rapi serta } \\
\text { fasilitas yang } \\
\text { memadai } \\
\text { membuat gairah } \\
\text { kerja saya } \\
\text { meningkat }\end{array}$ & $\mathbf{0}$ & 4 & 15 & 7 & 9 & 126 & 3,60 & Baik \\
\hline \multicolumn{7}{|c|}{ Total Rata-rata Skor } & & 3,76 & Baik \\
\hline
\end{tabular}

Tabel 9.

Jawaban Responden terhadap Motivasi

\begin{tabular}{|c|c|c|c|c|c|c|c|c|c|}
\hline \multirow[b]{2}{*}{ No } & \multirow{2}{*}{ Indikator } & \multicolumn{5}{|c|}{ Skor Jawaban } & \multirow{2}{*}{$\begin{array}{c}\text { Jumlah } \\
\text { Skor }\end{array}$} & \multirow{2}{*}{$\begin{array}{l}\text { Rata- } \\
\text { Rata }\end{array}$} & \multirow{2}{*}{ Kriteria } \\
\hline & & 1 & 2 & 3 & 4 & 5 & & & \\
\hline 1 & $\begin{array}{l}\text { Perusahaan } \\
\text { menempatkan saya } \\
\text { pada posisi yang } \\
\text { tepat }\end{array}$ & $\mathbf{0}$ & 2 & 10 & 8 & 15 & 141 & 4,03 & Baik \\
\hline 2 & $\begin{array}{l}\text { Saya merasa nyaman } \\
\text { pada saat } \\
\text { melaksanakan } \\
\text { pekerjaan }\end{array}$ & $\mathbf{0}$ & 5 & 16 & 8 & 6 & 120 & 3,43 & Baik \\
\hline 3 & $\begin{array}{l}\text { Perusahaan } \\
\text { memberikan saya } \\
\text { fasilitas rekreasi }\end{array}$ & $\mathbf{0}$ & 2 & 13 & 13 & 7 & 130 & 3,71 & Baik \\
\hline 4 & $\begin{array}{l}\text { Saya medapatkan } \\
\text { jaminan kesehatan } \\
\text { yang layak } \\
\text { diperusahaan. } \\
\qquad \text { Total }\end{array}$ & $\mathbf{0}$ & 4 & 10 & 13 & 8 & 130 & 3,71 & $\begin{array}{l}\text { Baik } \\
\text { Baik }\end{array}$ \\
\hline
\end{tabular}

Sumber: Data primer diolah, 2018 
Pada Tabel 10. nilai rata-rata tertinggi dimiliki oleh pernyataan 1 yaitu sebesar 4,11 yang memiliki arti bahwa karyawan mendapatkan gaji sesuai dengan jabatan mereka sehingga semangat yang dimiliki karyawan tetap tinggi dikarenakan gaji yang diberikan sesuai dengan kinerja yang mereka berikan. Namun dalam hal ini, pernyataan 2 memiliki rata-rata nilai terkecil yaitu 3,86 yang memiliki arti bahwa jumlah insentif yang diterima karyawan sudah sesuai dengan kinerja yang karyawan berikan ke perusahaan tetapi masih perlu ditingkatkan.

Tabel 10.

Jawaban Responden terhadap Kompensasi

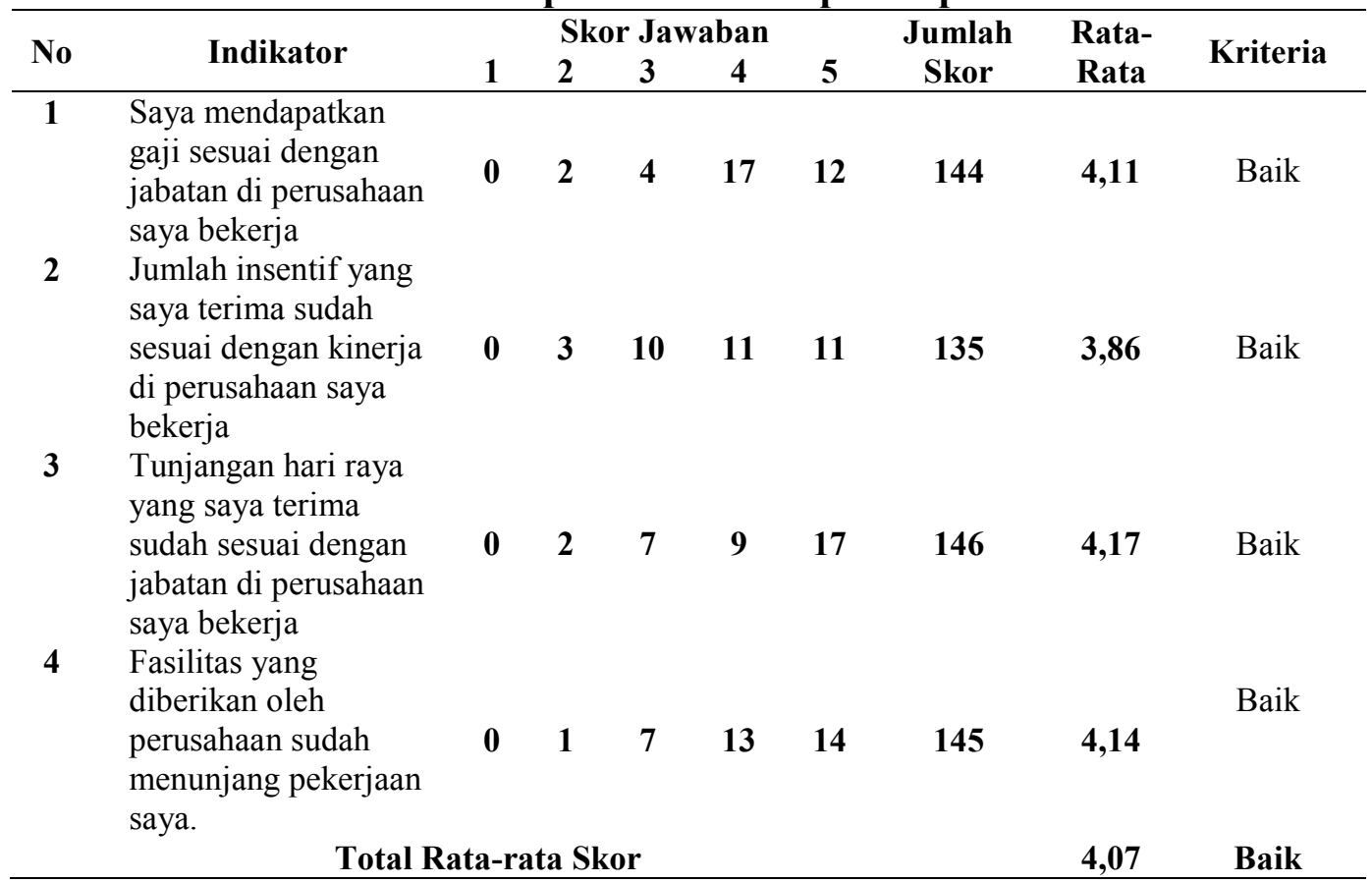

Sumber: Data primer diolah, 2018

Tabel 11. Penilaian responden dengan menggunakan 7 indikator terhadap variabel lingkungan kerja karyawan Bello Desain ditunjukkan pada Tabel 11.

Dari data yang disajikan pada Tabel 11 menunjukkan bahwa tujuh pernyataan mengenai lingkungan kerja karyawan memiliki total nilai rata-rata sebesar 3,71 yang berarti bahwa karyawan Bello Desain tergolong baik.

Nilai rata-rata tertinggi dimiliki oleh pernyataan 1 yaitu sebesar 4,09 yang memiliki arti bahwa penerangan ditempat kerja membantu karyawan bekerja. Namun dalam hal ini, pernyataan 7 memiliki rata-rata nilai terkecil yaitu 3,43 yang memiliki arti bahwa peralatan yang diberikan bekerja dengan baik.

Dari data pada Tabel 12. diketahui bahwa nilai $\beta_{1}$ adalah sebesar 0,459 menunjukkan adanya pengaruh positif motivasi $\left(\mathrm{X}_{1}\right)$ terhadap semangat kerja $(\mathrm{Y})$. Nilai $\beta_{2}$ adalah sebesar 0,663 menunjukkan adanya pengaruh positif kompensasi $\left(\mathrm{X}_{2}\right)$ terhadap semangat kerja $(\mathrm{Y})$. Nilai $\beta_{3}$ adalah sebesar 0,215 menunjukkan adanya pengaruh positif lingkungan kerja fisik $\left(\mathrm{X}_{3}\right)$ terhadap semangat kerja $(\mathrm{Y})$. Dari hasil tersebut, maka variabel motivasi, kompensasi, dan lingkungan kerja fisik berpengaruh terhadap semangat kerja karyawan. 
Tabel 11.

Jawaban Responden terhadap Lingkungan Kerja Fisik

\begin{tabular}{|c|c|c|c|c|c|c|c|c|c|}
\hline \multirow{2}{*}{ No } & \multirow{2}{*}{ Indikator } & \multicolumn{5}{|c|}{ Skor Jawaban } & \multirow{2}{*}{$\begin{array}{c}\text { Jumlah } \\
\text { Skor }\end{array}$} & \multirow{2}{*}{$\begin{array}{l}\text { Rata- } \\
\text { Rata }\end{array}$} & \multirow{2}{*}{ Kriteria } \\
\hline & & 1 & 2 & 3 & 4 & 5 & & & \\
\hline 1 & $\begin{array}{l}\text { Penerangan di tempat } \\
\text { saya bekerja } \\
\text { membantu pekerjaan } \\
\text { saya. }\end{array}$ & 0 & 0 & 12 & 8 & 15 & 143 & 4,09 & Baik \\
\hline 2 & $\begin{array}{l}\text { Temperatur ditempat } \\
\text { saya bekerja dapat } \\
\text { membuat saya lebih } \\
\text { nyaman saat bekerja. }\end{array}$ & $\mathbf{0}$ & 0 & 16 & 7 & 12 & 136 & 3,89 & Baik \\
\hline 3 & $\begin{array}{l}\text { Sirkulasi udara } \\
\text { ditempat saya bekerja } \\
\text { mengalir dengan baik. }\end{array}$ & 0 & 2 & 15 & 6 & 12 & 133 & $\mathbf{3 , 8 0}$ & Baik \\
\hline 4 & $\begin{array}{l}\text { Tempat kerja saya } \\
\text { jauh dari kebisingan. }\end{array}$ & $\mathbf{0}$ & 2 & 17 & 7 & 9 & 128 & 3,66 & Baik \\
\hline 5 & $\begin{array}{l}\text { Keamaanan di tempat } \\
\text { kerja membuat saya } \\
\text { dapat bekerja dengan } \\
\text { nyaman. }\end{array}$ & 0 & 1 & 19 & 7 & 8 & 127 & 3,63 & Baik \\
\hline 6 & $\begin{array}{l}\text { Saya memiliki } \\
\text { komunikasi yang baik } \\
\text { dengan rekan kerja }\end{array}$ & $\mathbf{0}$ & 6 & 13 & 8 & 8 & 123 & $\mathbf{3 , 5 1}$ & Baik \\
\hline 7 & $\begin{array}{l}\text { Peralatan di tempat } \\
\text { saya bekerjaberfungsi } \\
\text { dengan baik. }\end{array}$ & 0 & 6 & 16 & 5 & 8 & 120 & $\mathbf{3 , 4 3}$ & Baik \\
\hline & Total $\mathrm{F}$ & $a-r$ & 15 & & & & & 3,71 & Baik \\
\hline
\end{tabular}

Sumber: Data primer diolah, 2018

Tabel 12.

Hasil Analisis Regresi Linier Berganda

\begin{tabular}{lrrrrr}
\hline \multirow{2}{*}{ Model } & \multicolumn{2}{c}{$\begin{array}{c}\text { Unstandardized } \\
\text { Coefficients }\end{array}$} & $\begin{array}{c}\text { Standardized } \\
\text { Coefficients }\end{array}$ & \multirow{2}{*}{ T } & \multirow{2}{*}{ Sig. } \\
\cline { 2 - 5 } & \multicolumn{1}{c}{ B } & Std. Error & Beta & & \\
\hline (Constant) & -4.415 & 2.991 & & -1.476 & .150 \\
Motivasi & .459 & .169 & .291 & 2.719 & .011 \\
Kompensasi & .663 & .177 & .469 & 3.743 & .001 \\
Lingkungan Kerja & .215 & .084 & .308 & 2.548 & .016 \\
\hline
\end{tabular}

Sumber: Data primer diolah, 2018

Tabel 13.

Hasil Uji Normalitas

\begin{tabular}{cc}
\hline & Unstandardized Residual \\
\hline $\mathrm{N}$ & 35 \\
Asymp. Sig. (2-tailed) & 0,200 \\
\hline
\end{tabular}

Sumber: Data primer diolah, 2018 
Hasil pada Tabel 13. Menunjukkan bahwa nilai Asymp. Sig. (2-tailed) lebih besar dari taraf signifikansi yang ditetapkan yaitu 5 persen $(0,05)$, sebesar $0,200>$ 0,05 yang artinya data berdistribusi normal. Ini menunjukkan bahwa secara umum data yang ditemukan sudah memenuhi asumsi kenormalan data.

Tabel 14.

Hasil Uji Multikolinearitas

\begin{tabular}{|c|c|c|}
\hline \multirow[t]{2}{*}{ Model } & \multicolumn{2}{|c|}{ Collinearity Statistics } \\
\hline & Tolerance & VIF \\
\hline Motivasi & .895 & 1.117 \\
\hline Kompensasi & .655 & 1.526 \\
\hline Lingkungan kerja & .702 & 1.424 \\
\hline
\end{tabular}

Sumber: Data primer diolah, 2018

Berdasarkan Tabel 14. didapat tiga variabel bebas dalam penelitian ini nilai VIF-nya dibawah 10 dan tolerance nya mendekati 1 . Variabel motivasi memiliki tolerance lebih besar dari $0,10(0,895>0,10)$ dan VIF lebih kecil dari $10(1.117<10)$.

Variabel kompensasi memiliki tolerance lebih besar dari $0,10(0,655>0,10)$ dan VIF lebih kecil dari $10(1.526<10)$. Variabel lingkungan kerja memiliki tolerance lebih besar dari $0,10(0,702>0,10)$ dan VIF lebih kecil dari $10(1.424<10)$. Dengan demikian dapat dinyatakakan tidak terjadi multikolinieritas.

Tabel 15.

Hasil Uji Heteroskedastisitas

\begin{tabular}{lccccc}
\hline \multirow{2}{*}{ Model } & \multicolumn{2}{c}{$\begin{array}{c}\text { Unstandardized } \\
\text { Coefficients }\end{array}$} & $\begin{array}{c}\text { Standardized } \\
\text { Coefficients }\end{array}$ & T & Sig. \\
\cline { 2 - 4 } & $\mathbf{B}$ & Std. Error & Beta & & .607 \\
\hline (Constant) & 1.003 & 1.651 & & .548 \\
Motivasi & -.066 & .093 & -.128 & -.711 & .482 \\
Kompensasi & .179 & .098 & .386 & 1.831 & .077 \\
Lingkungan & -.040 & .047 & -.174 & -.857 & .398 \\
Kerja & & & & & \\
\hline
\end{tabular}

Sumber: Data primer diolah, 2018

Data pada Tabel 15. menunjukkan bahwa nilai Sig. dari variabel motivasi $\left(\mathrm{X}_{1}\right)$ sebesar 0,482, kompensasi $\left(\mathrm{X}_{2}\right)$ sebesar 0,077 dan lingkungan kerja $\left(\mathrm{X}_{3}\right)$ sebesar 0,398 . Nilai tersebut lebih besar dari 0,05 yang berarti tidak terdapat pengaruh antara variabel bebas terhadap absolute residual. Sehingga, model yang dibuat tidak mengandung gejala heteroskedastisitas.

Tabel 16.

Hasil Uji Kelayakan Model (Uji F)

\begin{tabular}{lccccc}
\hline \multicolumn{1}{c}{ Model } & Sum of Squares & Df & Mean Square & F & Sig. \\
\hline Regression & 404.517 & 3 & 134.839 & 22.107 & $.000^{\mathrm{b}}$ \\
Residual & 189.083 & 31 & 6.099 & & \\
Total & 593.600 & 34 & & & \\
\hline
\end{tabular}

Sumber: Data primer diolah, 2018 
Dari Tabel 16. Hasil Uji F dapat dilihat nilai signifikan yakni 0,000 kurang dari $0,05(0,000<0,05)$. Dengan kata lain model regresi dalam penelitian ini layak untuk digunakan sebagai alat analisis dan motivasi $\left(\mathrm{X}_{1}\right)$, kompensasi $\left(\mathrm{X}_{2}\right)$, lingkungan kerja fisik $\left(\mathrm{X}_{3}\right)$ berpengaruh signifikan secara serempak terhadap variabel terikat semangat kerja aryawan (Y) sehingga penelitian ini dapat dikatakan memenuhi uji kelayakan model atau model penelitian dinyatakan layak digunakan sebagai model regresi.

Tabel 17.

Hasil Analisis Koefisien Determinasi $\left(\mathbf{R}^{2}\right)$

\begin{tabular}{cccc}
\hline $\mathbf{R}$ & R Square & Adjusted R Square & Std. Error of the Estimate \\
\hline .825 & .681 & .651 & .2470 \\
\hline
\end{tabular}

Sumber: Data primer diolah, 2018

Berdasarkan Tabel 17. dapat dilihat nilai Adjusted $R$ Square sebesar 0,651 sehingga dapat dihitung persentase kontribusi motivasi, kompensasi, dan lingkungan kerja terhadap semangat kerja karyawan sebesar $0,651 \times 100 \%=65,1$ persen dengan sisa 34,9 persen dipengaruhi variabel lain diluar penelitian.

Hipotesis penelitian diuji menggunakan uji $t$ untuk menguji pengaruh masing - masing variabel bebas, yaitu motivasi $\left(\mathrm{X}_{1}\right)$, kompensasi $\left(\mathrm{X}_{2}\right)$ dan lingkungan kerja $\left(\mathrm{X}_{3}\right)$ terhadap variabel terikat semangat kerja $(\mathrm{Y})$.

Berdasarkan hasil regresi linear berganda pada Tabel 4.12 diketahui bahwa nilai signifikan untuk motivasi yakni 0,011 kurang dari $0,05(0,011<0,05)$, dengan nilai $t$ hitung 2,719 yang dibandingkan dengan nilai $t$ tabel dengan derajat kebebasan (degree of freedom) $\mathrm{N}-\mathrm{k}=35-4=31$ dan signifikan 0,05. Diperoleh nilai $t$ tabel sebesar 2,039 sehingga nilai $t$-hitung $>t$-tabel $(2,719>2,039)$. Dengan demikian, $\mathrm{H}_{1}$ diterima.

Berdasarkan hasil regresi linear berganda pada Tabel 4.12, diketahui bahwa nilai signifikan untuk kompensasi yakni 0,001 kurang dari 0,05 $(0,001<0,05)$, dengan nilai thitung 3,743 yang dibandingkan dengan nilai t tabel dengan derajat kebebasan (degree of freedom ) $\mathrm{N}-\mathrm{k}=35-4=31$ dan signifikan 0,05. Diperoleh nilai t tabel sebesar 2,039 sehingga nilai $t$-hitung $>t$-tabel $(3,743>2,039)$. Dengan demikian, $\mathrm{H}_{2}$ diterima.

Berdasarkan hasil regresi linear berganda pada Tabel 4.12, diketahui bahwa nilai signifikan untuk lingkungan kerja yakni 0,016 kurang dari $0,05(0,016<0,05)$, dengan nilai t hitung 2,548 yang dibandingkan dengan nilai t tabel dengan derajat kebebasan (degree of freedom) $\mathrm{N}-\mathrm{k}=35-4=31$ dan signifikan 0,05. Diperoleh nilai $t$ tabel sebesar 2,039 sehingga nilai $t$-hitung $>t$-tabel $(2,548>2,039)$. Dengan demikian, $\mathrm{H}_{3}$ diterima.

Hasil pengujian hipotesis terbukti bahwa motivasi berpengaruh positif dan signifikan terhadap semangat kerja karyawan. Yang berarti apabilan motivasi semakin tinggi maka semangat kerja karyawan Bello Desain Singaraja akan meningkat dan sebaliknya, jika tingkat motivasi karyawan rendah maka semangat kerja yang dimiliki karyawan di Bello Desain Singaraja akan menurun.

Hasil penelitian ini sesuai dengan hipotesis satu $\left(\mathrm{H}_{1}\right)$ yang diajukan dan sesuai dengan hasil penelitian yang dilakukan oleh Zameer et al. (2014), Liu (2015) yang 
menyatakan bahwa motivasi kerja berpengaruh positif terhadap semangat kerja. Artinya, pemberian motivasi kerja yang baik oleh perusahaan mampu meningkatkan semangat kerja karyawan untuk bekerja lebih baik.

Hasil pengujian hipotesis terbukti bahwa kompensasi berpengaruh positif dan signifikan terhadap semangat kerja karyawan. Yang berarti apabilan kompensasi semakin tinggi maka semangat kerja karyawan Bello Desain Singaraja akan meningkat dan sebaliknya, jika kompensasi karyawan rendah maka semangat kerja yang dimiliki karyawan di Bello Desain Singaraja akan menurun. Hasil penelitian ini sesuai dengan hipotesis dua $\left(\mathrm{H}_{2}\right)$ yang diajukan dan sesuai dengan hasil penelitian yang dilakukan oleh Sudiardhita et al. (2018) yang berisi kompensasi berpengaruh signifikan terhadap semangat kerja karyawan. Hasil penelitian ini juga mendukung pendapat tentang kompensasi bahwa kompensasi merupakan salah satu faktor naik turunnya semangat kerja karyawan terhadap perusahaan.

Hasil pengujian hipotesis terbukti bahwa lingkungan kerja berpengaruh positif dan signifikan terhadap semangat kerja karyawan. Yang berarti semakin baik kondisi lingkungan kerja maka semangat kerja karyawan di Bello Desain Singaraja akan meningkat dan sebaliknya, jika kondisi lingkungan kerja kurang baik maka semangat yang dimiliki karyawan di Bello Desain Singaraja akan menurun.

Hasil penelitian ini sesuai dengan hipotesis tiga $\left(\mathrm{H}_{3}\right)$ yang diajukan dan sesuai dengan hasil penelitian yang dilakukan oleh Mangkunegara \& Agustine (2016) mengatakan bahwa lingkungan kerja berpengaruh positif terhadap semangat kerja pegawai. Renah \& Setyadi (2014) menyatakan pula bahwa terdapat hubungan yang signifikan antara lingkungan kerja dengan semangat kerja karyawan.

Beberapa implikasi dari hasil penelitian ini, yakni pertama terbukti bahwa motivasi, kompensasi, dan lingkungan kerja fisik berpengaruh positif terhadap semangat kerja. Karyawan merasa penempatan posisi yang diberikan oleh perusahaan sesuai dengan kemampuan yang dimiliki, oleh karena itu dengan menempatkan karyawan posisi yang tepat dapat meningkatkan semangat kerja.

Kedua, melalui penelitian ini diketahui bahwa kompensasi di Bello Desain dalam keadaan baik. Tunjangan yang diterima karyawan sudah sesuai dengan jabatan yang dimiliki, oleh karena itu dengan memberi tunjangan sesuai dengan jabatan tersebut dapat meningkatkan semangat kerja karyawan.

Ketiga, dapat diketahui bahwa lingkungan kerja fisik di Bello Desain dalam keadaan baik. Penerangan yang diberikan perusahaan membantu karyawan untuk bekerja sehingga karyawan dapat menyelesaikan pekerjaannya sesuai dengan waktu yang di berikan oleh perusahaan.

\section{SIMPULAN}

Berdasarkan hasil analisis penelitian dan hasil pembahasan pada bab sebelumnya maka simpulan dari penelitian ini adalah sebagai berikut: Motivasi berpengaruh positif terhadap semangat kerja karyawan Bello Desain Singaraja. Hal ini berarti apabila jika motivasi semakin meningkat maka semangat kerja karyawan semakin meningkat pula. Kompensasi berpengaruh positif terhadap semangat kerja karyawan Bello Desain Singaraja. Hal ini berarti apabila kompensasi diberikan meningkat maka semangat kerja karyawan meningkat pula. 
Lingkungan kerja berpengaruh positif terhadap semangat kerja karyawan Bello Desain Singaraja. Hal ini berarti apabila jika lingkungan kerja semakin meningkat maka semangat kerja karyawan meningkat pula.

Saran yang dapat diberikan berdasarkan hasil analisis dan pembahasan adalah sebagai berikut: Pihak perusahaan hendaknya harus selalu memotivasi karyawan dengan cara memberikan kenyamanan di perusahaan seperti menjalin hubungan yang baik dan membangun kepercayaan antar karyawan

Pihak perusahaan diharapkan sebisa mungkin untuk membuat sistem pembagian jumlah insentif yang diterima karyawan sesuai dengan beban kerja serta tanggung jawab yang diberikan ke karyawan agar para karyawan tetap memiliki semangat kerja yang tinggi pada perusahaan.

Bagi pihak perusahaan untuk menciptakan lingkungan kerja yang kondusif, dan memberikan peralatan yang berfungsi dengan baik agar mempermudah karyawan dalam bekerja.

\section{REFERENSI}

Agustina, S., \& Suryani, N. (2016). Pengaruh Kompensasi, Komunikasi Dalam Organisasi, Dan Lingkungan Kerja Fisik Terhadap Semangat Kerja Guru Tidak Tetap. Economic Education Analysis Journal, 5(6), 1-20.

Annisa, N. (2015). Pengaruh Lingkungan Kerja Terhadap Semangat Kerja Pegawai Di Kantor Kelurahan Air Putih Samarinda. E-Journal Administrasi Negara, 3(5), 1452-1463.

Banks, S., Kuofie, H., \& Branch, R. (2015). Education Leadership Styles Impact on Work Performance and Morale of Staff. Journal of Marketing and Management, 6(2), 87-105.

Chukwuma, E. M. (2014). Effect of Motivation on Employee Productivity: A Study of Manufacturing Companies in Nnewi. International Journal of Managerial Studies and Research (IJMSR), 2(7), 137-147.

Elqadri, Z. M., \& Wardoyo, D. T. W. (2015). The Influence Of Motivation And Discipline Work Againt Employee Work Productivity Tona'an Markets. Review Of European Studies, 7(2), 1-20.

Ependi, Z. (2014). Pengaruh Kompensasi dan Lingkungan Kerja Terhadap Semangat Kerja Karyawan Pada Perusahaan Daerah Air Minum (PDAM) Tirta Kampar Bangkinang Kota. Jurnal Manajemen, 1(1), 1-12.

Gîlmeanu, M. R. (2015). Theoretical Considerations On Motivation At The Work Place, Job Satisfaction And Individual Performance. Valahian Journal of Economic Studies, 6(3), 69-80.

Hasanah, R. (2016). Pengaruh Lingkungan Kerja Terhadap Semangat Kerja Karyawan Bagian Service Pada PT. United Tracktor Tbk Pekanbaru. Jom 
Fisip, 3(1), 1-20.

Kusuma, Y. W. (2016). PENGARUH MOTIVASI KERJA DAN INSENTIF TERHADAP SEMANGAT KERJA KARYAWAN CV. F.A MANAGEMENT. Jirm, 5(2), 1-20.

Liu, P. (2015). Motivating Teachers' Commitment To Change Through Transformational School Leadership In Chinese Urban, Upper Secondary Schools. Jurnal Of Educational Administration, 53(6), 735-754.

Mangkunegara, A. P., \& Agustine, R. (2016). Effect Of Training, Motivation And Work Environment On Physicians' Performance. Academic Journal Of Interdisciplinary Studies, 5(1), 1-20.

Omolo, P. A. (2015). Effect Of Motivation On Employee Performance Of Commercial Banks In Kenya: A Case Study Of Kenya Commercial Bank In Migori County. International Journal of Human Resource Studies, 5(2), 87103.

Osa, I. G., \& Amos, I. O. (2014). The Impact Of Organizational Commitment On Employees Productivity: A Case Study Of Nigeria Brewery. International Journal of Research in Business Management, 2(9), 107-122.

Pravasta, I. G. N. G., \& Sintaasih, D. K. (2014). Kompensasi Dan Motivasi: Pengaruhnya Terhadap Semangat Kerja Karyawan PT. Tjendana Mandra Sakti Denpasar. E-Jurnal Manajemen, 1(2), 1320 - 1341.

Ratnasari, S. L., \& Sudjahjo, G. (2017). Pengaruh Kepemimpinan Transformasional dan Lingkungan Kerja Terhadap Semangat Kerja Tenaga Kependidikan. Jurnal Inspirasi Bisnis Dan Manajemen, 1(2), 99-112.

Rawat, S. R. (2015). Impact Of Transformational Leadership Over Employee Morale And Motivation. Indian Journal of Science and Technology, 8(6), 113.

Renah, A., \& Setyadi, D. (2014). The Influence Of Organizational Culture, Working Environment And Educational Training On Motivation And Performance Of Government Employees At West Kutai Regency East Kalimantan. European Journal Of Business And Management, 6(30), 1-20.

Riyanto, S., Sutrisno, A., \& Ali, H. (2017). The Impact Of Working Motivation And Working Environment On Employees Performance In Indonesia Stock Exchange. International Review Of Management And Marketing, 7(3), 342348.

Shaban, O. (2017). The Effect of Low Morale and Motivation on Employees' 
Productivity \& Competitiveness in Jordanian Industrial Companies. International Business Research, 10(7), 1-12.

Sharma, R., Sharma, P., \& Pandey, V. K. (2016). Motivation And Quality Of Work Life (Qwl) Programmes As Predictors Of Employee Commitment: A Study Of Service Organisation In Gwalior Region. Journal of Organisation and Human Behaviour, 5(1), 36-41.

Sudiardhita, K. I. R., Mukhtar, S., Hartono, B., Herlitah, Sariwulan, T., \& Nikensari, S. I. (2018). The effect of compensation, motivation of employee and work satisfaction to employee performance PT. Bank XYZ (Persero) Tbk. Academy of Strategic Management Journal, 17(4), 1-14.

Syahreza, D. S., Lumbanraja, P., Dalimunthe, R. F., \& Absah, Y. (2017). Compensation, Employee Performance, and Mediating Role of Retention: A Study of Differential Semantic Scales. Europian Research Studies Journal, 10(10), 151-159.

Utamajaya, I. D. G. A. P., \& Sriathi, A. A. A. (2015). Pengaruh Motivasi, Komunikasi, Serta Lingkungan Kerja Fisik Terhadap Semangat Kerja Karyawan Pada Fuji Jaya Motor Gianyar. E-Jurnal Manajemen Unud, 4(6), 1504-1524.

Widiantara, D. S. N., \& Wasnury, R. (2015). Pengaruh Kepemimpinan dan Lingkungan Kerja Terhadap Semangat Kerja Pegawai Puskesmas Sidomulyo Pekanbaru. Jom FEKON, 2(1), 1-20.

Yasa, I. K. M. S., \& Wibawa, I. M. A. (2015). Pengaruh Kompensasi Finansial, Komunikasi Dan Lingkungan Kerja Fisik Terhadap Semangat Kerja Karyawan. E-Jurnal Manajemen Universitas Udayana, 4(3), 1-20.

Zameer, H., Ali, S., Nisar, W., \& Amir, M. (2014). The Impact Of The Motivation On The Employee's Performance In Beverage Industry Of Pakistan. International Journal of Academy Research in Accounting, Finance \& Management Sciences, 4(1), 293-298. 